\title{
TYPE 2 DIABETES MELLITUS ASSOCIATION WITH SEXUAL DYSFUNCTION IN WOMEN
}

\author{
Sreenivasa Murthy L1, Sreenivasa Rao Sudulagunta2 ${ }^{2}$ Shiva Kumar Bangalore Raja3 ${ }^{3}$ Bhaktavatchalam ${ }^{4}$, Mahesh Babu Sodalagunta ${ }^{5}$, \\ Mona Sepehrar6, Munawar Dhanish M77, Keshava Chandra Thejaswi ${ }^{8}$
}

\author{
1 Professor, Department of Medicine, Dr. B. R. Ambedkar Medical College. \\ ${ }^{2}$ Senior Resident, Department of Internal Medicine, Dr. B. R. Ambedkar Medical College. \\ ${ }^{3}$ Professor, Department of General Medicine, Dr. B. R. Ambedkar Medical College. \\ ${ }_{4}^{4}$ Professor and HOD, Department of General Medicine, Dr. B. R. Ambedkar Medical College. \\ ${ }_{5}^{5}$ Postgraduate Student, Department of General Medicine, Dr. B. R. Ambedkar Medical College. \\ ${ }^{6}$ Doctor of Pharmacy, Dr. B. R. Ambedkar Medical College. \\ 7Junior Resident, Department of General Medicine, Dr. B. R. Ambedkar Medical College. \\ 8Junior Resident, Department of General Medicine, Dr. B. R. Ambedkar Medical College.
}

\section{ABSTRACT}

\section{BACKGROUND}

Diabetes mellitus causes medical, psychological and sexual complications. Sexual dysfunction (SD) is one of the important problems in type 2 diabetic patients. Sexual disorders have been extensively studied in men, but in women only few studies were performed. Hence, this study is undertaken.

This study is aimed to find the prevalence of sexual problems in women with type 2 diabetes mellitus.

\section{MATERIALS AND METHODS}

This cross-sectional study was conducted over a period of 18 months from October 2014 to September 2016. Patients recruited were type 2 diabetics aged between 18 years and 65 years. A total of 500 patients were given the questionnaire, of which 375 patients answered completely and returned it. Female Sexual Function Index (FSFI) and The Hospital Anxiety and Depression Scale (HADS) were used in questionnaire. A value of $\mathrm{P}<0.05$ was considered to be significant.

\section{RESULTS}

Out of 375 patients recruited in to study, $28.8 \%$ were in $40-49$ years age group. The mean age of patients was $43 \pm 15.8$ years, the mean duration of DM was $8.87 \pm 6.7$ years, the mean of the body mass index (BMI) was $31.86 \pm 5.76$, and the mean of the last HbA1c was 8.12 \pm 2.78 . The mean of the Female Sexual Function Index (FSFI) was found to be 22. The prevalence of SD was observed to be 79.73\%. Among 299 patients who reported sexual dysfunction, 171 patients (57.19\%) (CI: 49.6-67.8) reported problems in lubrication, 153 patients (51.17\%) (CI: 41.2-59.6) complained of decreased sexual desire, 147 patients (47.49\%) (CI: 40.104-58.8) had problems with arousal, 103 patients (34.44\%) (CI: 31.6-54.7) had dyspareunia, 189 patients (63.21\%) (CI: 32.7-68.8) complained of orgasmic dysfunction and 259 patients (86.62\%) (CI: 65.0-89.7) reported problems in sexual satisfaction.

\section{CONCLUSION}

Our study showed that there is high prevalence of sexual dysfunction (SD) in women with type 2 diabetes mellitus (DM). Our study also showed that there is statistical significant association between complications of diabetes mellitus and prevalence of sexual dysfunction. Patients with type 2 diabetes mellitus have higher prevalence of depression and anxiety. There is strong correlation between sexual dysfunction and age of the patient, BMI, HBA1C levels and duration of diabetes mellitus.

\section{KEYWORDS}

Diabetes Mellitus, Female, Sexual Dysfunction, Obesity.

HOW TO CITE THIS ARTICLE: Murthy SL, Sudulagunta SR, Raja SKB, et al. Type 2 diabetes mellitus association with sexual dysfunction in women. J. Evolution Med. Dent. Sci. 2016;5(99):7252-7256, DOI: 10.14260/Jemds/2016/1640

\section{BACKGROUND}

Diabetes mellitus (DM) is a group of metabolic diseases characterised by hyperglycaemia resulting from defects in insulin secretion, insulin action, or both [Figure 1]. Diabetes mellitus is probably one of the oldest known diseases to

Financial or Other, Competing Interest: None.

Submission 22-11-2016, Peer Review 05-12-2016,

Acceptance 07-12-2016, Published 12-12-2016.

Corresponding Author:

Dr. Sreenivasa Murthy L,

Professor, Department of Medicine,

Dr. B.R. Ambedkar Medical College,

K. G. Halli,

Bangalore-560045.

E-mail: drsreenivasamurthy@gmail.com

DOI: $10.14260 /$ jemds/2016/1640 mankind. DM was first recorded in Egyptian manuscript about 3000 years ago.[1] In 1936, the clear distinction between type 1 and type 2 DM was done.[2] Type 2 DM was described as a component of metabolic syndrome for the first time in 1988.[3] Type $2 \mathrm{DM}$ is the commonest form of DM characterised by hyperglycaemia, insulin resistance, and relative insulin deficiency.[4] Type $2 \mathrm{DM}$ results due to interaction between genetic, environmental and behavioural risk factors. [5],[6]

People living with type $2 \mathrm{DM}$ are more vulnerable to various forms of both short-term and long-term complications, and risk of premature death. As of 2015, an estimated 415 million people are affected with diabetes worldwide[7], with type 2 DM contributing about $90 \%$ of the cases.[8][9] This number represents $8.3 \%$ of the adult population[10], with almost equal rates in both women and men.[11] From 2012 to 2015, an estimate of 1.5 to 5.0 million deaths each year 
resulted from diabetes. Diabetes doubles a person's risk of death. The number of people with diabetes is expected to reach 592 million by 2035.

The global economic cost of diabetes in 2014 was estimated to be $\$ 612$ billion USD.[12] In the United States, diabetes cost $\$ 245$ billion in 2012.[13] Rates of type 2 diabetes have increased drastically since 1960 in parallel with obesity.[14] As of 2013, there were approximately 368 million people diagnosed with the type $2 \mathrm{DM}$ compared to around 30 million in 1985.[15],[16] This increase is due to ageing of the global population, a reduction in exercise, and increasing rates of obesity.

The five countries with the highest number of people affected with diabetes as of 2000 are India having 31.7 million, China 20.8 million, the United States 17.7 million, Indonesia 8.4 million, and Japan 6.8 million.[17] It is recognised as a global epidemic by the World Health Organization.[18] Usually, it begins in middle or older age. Type 2 diabetes is associated with a ten-year shorter life expectancy. Diabetes was one of the first diseases described. The importance of insulin in the disease was determined in the 1920s. ${ }^{[19]}$ A number of lifestyle factors are known to be important to the development of type 2 DM.[20] Lifestyle factors include sedentary lifestyle, physical inactivity, cigarette smoking and excessive consumption of alcohol.[21] Obesity contributes to approximately $55 \%$ of cases of type 2 DM.[22]

Sexuality is a complex process, coordinated by the neurologic, vascular and endocrine systems. ${ }^{[23]}$ Female SD is classified into desire, arousal, orgasmic and sexual pain disorders. Sexual pain disorders include dyspareunia and vaginismus.[24] Estimates of women who have sexual dysfunction in normal outpatient population range from 19 to $50 \%[25],[26]$ and the number increases to 68 to $75 \%$ when sexual dissatisfaction and other problems are included.[27] Diabetes mellitus causes medical, sexual and psychological complications.[28] SD can be an early manifestation of diabetes mellitus.[29]

The aim is to study the clinical profile in type 2 DM patients, determine the prevalence of sexual dysfunction of female patients, assess the role of comorbidities, psychological factors and other factors on sexual function.

\section{MATERIALS AND METHODS}

This cross-sectional study was conducted over a period of 18 months from October 2014 to September 2016. Patients recruited were type 2 diabetics aged between 18 years and 65 years. All patients recruited were married and had a stable relationship for at least 2 years. Patients with hypothyroidism, chronic kidney disease, liver disease, malignancies, pregnancy, mastectomy, hysterectomy, oophorectomy, presence of psychological/sexual disorder in spouse, psychological disorder before diabetes onset, usage of psychotropic drugs and type 1 diabetes were excluded. The data was obtained from 3 hospitals and 4 clinics where they treat general medicine patients assuring the privacy of patients. Approval from the Institutional Ethics Committee and permission from the respective hospitals were obtained before starting the study.

A total of 500 patients were given the questionnaire, of which 375 patients answered completely and returned it. The demographic data (age, sex), clinical features, comorbid conditions, duration of diabetes, investigations including
HBA1C, lipid profile, complications (Micro and macrovascular), drug usage, results of the treatment and adverse effects were analysed. The questionnaires used were 1. Demographic data 2. Female Sexual Function Index (FSFI) and 3. Hospital Anxiety and Depression Scale (HADS).

Female Sexual Function Index (FSFI) is used for assessing sexual function in women using 6 domains and 19 items. Six domains of female sexual functions are: desires, arousal, lubrication, orgasm, satisfaction and pain during sexual intercourse.[30] Hospital Anxiety and Depression Scale (HADS) is a screening tool used to measure psychological distress and is sensitive to changes during the course of illness and in response to medical and psychological management.[31]

HADS consists of 14 items and two subscales, anxiety and depression; each item is rated on a four-point scale. The maximum score for anxiety and depression subscales is 21 . Scores $0-7$, are considered to be "normal", while scores 11 or more points to a psychological morbidity, and scores 8-10 indicates a borderline status. ${ }^{[32]}$ Frequencies, 95\% CI, OR and its $95 \%$ CI were calculated and student $\mathrm{t}$-test and $\mathrm{x}^{2}$ were used to detect the association between variables. SPSS (Statistical Package for Social Sciences, V18) was used for statistical analysis. A p value of $<0.05$ is considered as statistically significant.

\section{RESULTS}

Out of 375 patients recruited in to study, 108 patients (28.8\%) were in 40-49 years age group, followed by 89 patients $(23.7 \%)$ in $30-39$ years age group, 86 patients $(22.9 \%)$ in 50 59 years age group, and 81 patients $(21.6 \%)$ in 20 -29years age group. The mean age of patients was $43 \pm 15$. 8 years, the mean duration of DM was $8.87 \pm 6.7$ years, the mean of the body mass index (BMI) was $31.86 \pm 5.76$, and the mean of the last HbA1c was $8.12 \pm 2.78$. The demographic characteristics of the study are represented in table 1 . In these patients, with the complications of diabetes mellitus, diabetic neuropathy was the most common (57.6\%), followed by diabetic nephropathy (26.67\%), diabetic retinopathy (17.06\%), and cardiovascular problems (14.93\%).

The mean of the Female Sexual Function Index (FSFI) was found to be 22 . The prevalence of SD was observed to be 79.73\% (CI: 70.6-85.8) (299/375 patients). Among 299 patients who reported sexual dysfunction, 171 patients (57.19\%) (CI: 49.6-67.8) reported problems in lubrication, 153 patients (51.17\%) (CI: 41.2-59.6) complained of decreased sexual desire, 147 patients (47.49\%) (CI: 40.10458.8) had problems with arousal, 103 patients (34.44\%) (CI: 31.6-54.7) had dyspareunia, 189 patients (63.21\%) (CI: $32.7-$ 68.8) complained of orgasmic dysfunction and 259 patients (86.62\%) (CI: 65.0-89.7) reported problems in sexual satisfaction [Table 3].

Regarding the results of the Hospital Anxiety and Depression Scale (HADS) for frequency of anxiety and depression [Table 4], 119 patients (31.73\%) had no anxiety; mild anxiety was present in 125 (33.33\%) patients, moderate anxiety was present in $90(24 \%)$ patients, and severe anxiety was observed in $41(10.93 \%)$ patients. No depression was observed in 139 (37.06\%), Mild depression was present in 156 (41.6\%) patients, Moderate depression was present in 55 $(14.66 \%)$ patients and severe depression was present in 25 (6.66\%) patients. 
Table 5 represents association between presence of SD and demographics. The results showed that there was significant association between the presence of SD and age of the patients, BMI, HbA1c level, duration of DM and the presence of menopause $(\mathrm{P}=0.02)$, No statistically significant relationship was observed between presence of SD and hypertension, type of treatment $(\mathrm{P}=0.16)$ and type of oral hypoglycaemic agents $(\mathrm{P}=0.58)$.

\begin{tabular}{|c|c|}
\hline Age Group & $\begin{array}{c}\text { Total No. of } \\
\text { Patients (375) }\end{array}$ \\
\hline 20-29 years & $81(21.6 \%)$ \\
\hline 30-39 years & $89(23.7 \%)$ \\
\hline 40-49 years & $108(28.8 \%)$ \\
\hline $50-59$ years & $86(22.9 \%)$ \\
\hline 60-65 years & $11(2.93 \%)$ \\
\hline \multicolumn{2}{|l|}{ Education Level } \\
\hline Illiterate & $25(6.66 \%)$ \\
\hline Primary education & $100(26.66 \%)$ \\
\hline Secondary education & $95(25.33 \%)$ \\
\hline Tertiary education & $155(41.33 \%)$ \\
\hline \multicolumn{2}{|c|}{ Socio-economic status (Kuppuswamy's Scale for 2016) } \\
\hline Upper & $73(19.46 \%)$ \\
\hline Upper middle & $108(28.8 \%)$ \\
\hline Lower middle & $75(20 \%)$ \\
\hline Upper lower & $90(24 \%)$ \\
\hline Lower & $29(7.73 \%)$ \\
\hline \multicolumn{2}{|l|}{ Residency } \\
\hline Urban & $274(73.07 \%)$ \\
\hline Rural & $101(26.93 \%)$ \\
\hline \multicolumn{2}{|l|}{ Occupation } \\
\hline Employed & $237(63.2 \%)$ \\
\hline Housewife & $138(36.8 \%)$ \\
\hline \multicolumn{2}{|l|}{ Hypertension } \\
\hline Yes & $129(34.4 \%)$ \\
\hline No & $246(65.6 \%)$ \\
\hline \multicolumn{2}{|l|}{ Ongoing Treatment } \\
\hline Oral hypoglycaemic agent & $228(60.8 \%)$ \\
\hline Insulin & $79(21.06 \%)$ \\
\hline Oral hypoglycaemic agent and Insulin & $49(13.06 \%)$ \\
\hline Only diet and exercise & $19(5.06 \%)$ \\
\hline $\begin{array}{c}\text { Table 1. The Demographic Charac } \\
\text { Group }\end{array}$ & s of the Study \\
\hline
\end{tabular}

\begin{tabular}{|c|c|c|c|c|}
\hline 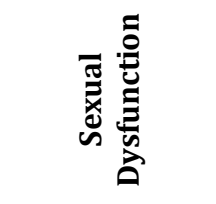 & 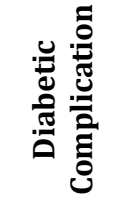 & 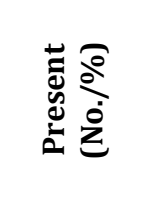 & 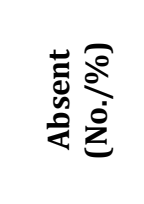 & $\frac{0}{3}$ \\
\hline \multirow{2}{*}{$\begin{array}{c}\text { DM } \\
\text { neuropathy }\end{array}$} & $\begin{array}{c}\text { Present } \\
(216) \\
\end{array}$ & $\begin{array}{c}181 \\
(83.79 \%) \\
\end{array}$ & $\begin{array}{c}35 \\
(16.20 \%) \\
\end{array}$ & \multirow{2}{*}{0.01} \\
\hline & $\begin{array}{c}\text { Absent } \\
(159)\end{array}$ & $\begin{array}{c}115 \\
(72.33 \%)\end{array}$ & $\begin{array}{c}44 \\
(27.67 \%)\end{array}$ & \\
\hline \multirow{2}{*}{$\begin{array}{c}\mathrm{DM} \\
\text { retinopathy }\end{array}$} & $\begin{array}{c}\text { Present } \\
(64)\end{array}$ & $\begin{array}{c}58 \\
(90.62 \%) \\
\end{array}$ & $\begin{array}{c}6 \\
(9.38 \%) \\
\end{array}$ & \multirow{2}{*}{0.02} \\
\hline & $\begin{array}{c}\text { Absent } \\
(311)\end{array}$ & $\begin{array}{c}242 \\
(77.81 \%) \\
\end{array}$ & $\begin{array}{c}69 \\
(22.19 \%) \\
\end{array}$ & \\
\hline \multirow{2}{*}{$\begin{array}{c}\text { DM } \\
\text { nephropathy }\end{array}$} & $\begin{array}{c}\text { Present } \\
(100)\end{array}$ & $\begin{array}{c}79 \\
(79 \%) \\
\end{array}$ & $\begin{array}{c}21 \\
(21 \%)\end{array}$ & \multirow{2}{*}{0.16} \\
\hline & $\begin{array}{c}\text { Absent } \\
(275)\end{array}$ & $\begin{array}{c}234 \\
(85.09 \%) \\
\end{array}$ & $\begin{array}{c}41 \\
(14.91 \%) \\
\end{array}$ & \\
\hline $\begin{array}{c}\text { Cardiovascular } \\
\text { complications }\end{array}$ & $\begin{array}{c}\text { Present } \\
(56)\end{array}$ & $\begin{array}{c}35 \\
(62.5 \%) \\
\end{array}$ & $\begin{array}{c}21 \\
(37.5 \%) \\
\end{array}$ & 0.002 \\
\hline
\end{tabular}

\begin{tabular}{|c|c|c|c|c|}
\hline & $\begin{array}{c}\text { Absent } \\
(319)\end{array}$ & 262 & 57 & \\
$(82.13 \%)$ & $(17.87 \%)$ & \\
\hline \multicolumn{3}{|c|}{ Table 2. Complications of Diabetes Mellitus (DM) and } \\
\hline
\end{tabular}

\begin{tabular}{|c|c|}
\hline $\begin{array}{c}\text { Sexual } \\
\text { Dysfunction } \\
\text { Variables }\end{array}$ & $\begin{array}{c}\text { Number } \\
\text { (Percentage) } \\
\mathbf{2 9 9}(\mathbf{1 0 0 \% )}\end{array}$ \\
\hline Problems in lubrication & $171(57.19 \%)$ \\
\hline Decreased sexual desire & $153(51.17 \%)$ \\
\hline Problems with arousal & $142(47.49 \%)$ \\
\hline Dyspareunia & $103(34.44 \%)$ \\
\hline Orgasmic dysfunction & $189(63.21 \%)$ \\
\hline Problems in sexual satisfaction & $259(86.62 \%)$ \\
\hline Table 3. Components of Sexual Dysfunction (SD) \\
\hline
\end{tabular}

\begin{tabular}{|c|c|}
\hline Variable & Number (Percentage) \\
\hline No anxiety & $119(31.73 \%)$ \\
\hline Mild anxiety & $125(33.33 \%)$ \\
\hline Moderate anxiety & $90(24 \%)$ \\
\hline Severe anxiety & $41(10.93 \%)$ \\
\hline No depression & $139(37.06 \%)$ \\
\hline Mild depression & $156(41.6 \%)$ \\
\hline Moderate depression & $55(14.66 \%)$ \\
\hline Severe depression & $25(6.66 \%)$ \\
\hline \multicolumn{2}{|c|}{$\begin{array}{c}\text { Table 4. Hospital Anxiety and Depression Scale (HADS) } \\
\text { Assessment Results }\end{array}$} \\
\hline
\end{tabular}

\begin{tabular}{|c|c|c|c|}
\hline Variables & $\begin{array}{c}\text { Sexual } \\
\text { Dysfunction } \\
\text { Present } \\
(\mathbf{2 9 9 / 3 7 5 )}\end{array}$ & $\begin{array}{c}\text { Sexual } \\
\text { Dysfunction } \\
\text { Absent } \\
\mathbf{( 7 6 / 3 7 5 )}\end{array}$ & $\begin{array}{c}\text { P } \\
\text { Value }\end{array}$ \\
\hline $\begin{array}{c}\text { Age of } \\
\text { patient }\end{array}$ & $45.62 \pm 12.8$ & $36.54 \pm 10.6$ & 0.0001 \\
\hline BMI & $35.6 \pm 5.7$ & $30.2 \pm 6.6$ & 0.0001 \\
\hline $\begin{array}{c}\text { HbA1C } \\
\text { levels }\end{array}$ & $8.34 \pm 2.8$ & $7.62 \pm 3.4$ & 0.0566 \\
\hline $\begin{array}{c}\text { Duration of } \\
\text { diabetes } \\
\text { mellitus }\end{array}$ & $8.86 \pm 6.9$ & $6.68 \pm 5.8$ & 0.0116 \\
\hline \multicolumn{2}{|c|}{ Table 5. Demographics and Sexual Dysfunction } \\
\hline
\end{tabular}

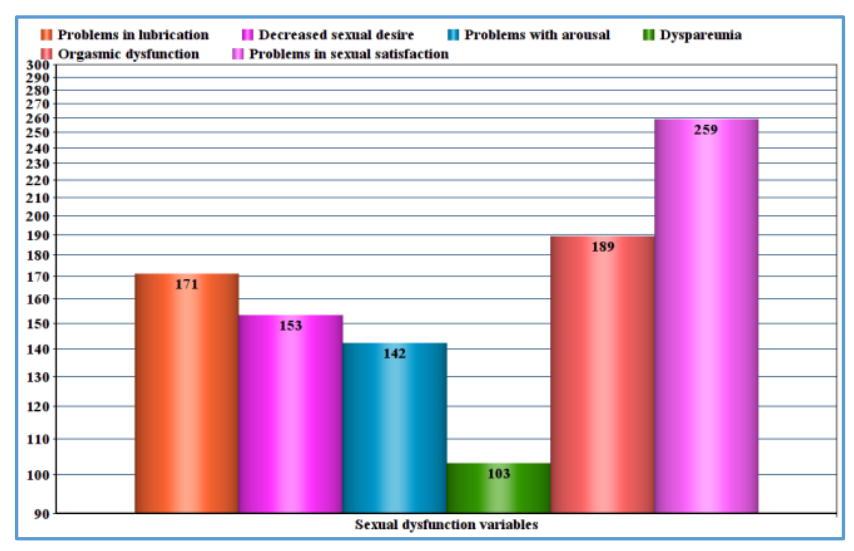

Figure 1. Sexual Dysfunction in Type 2 Diabetes Mellitus Study Group 


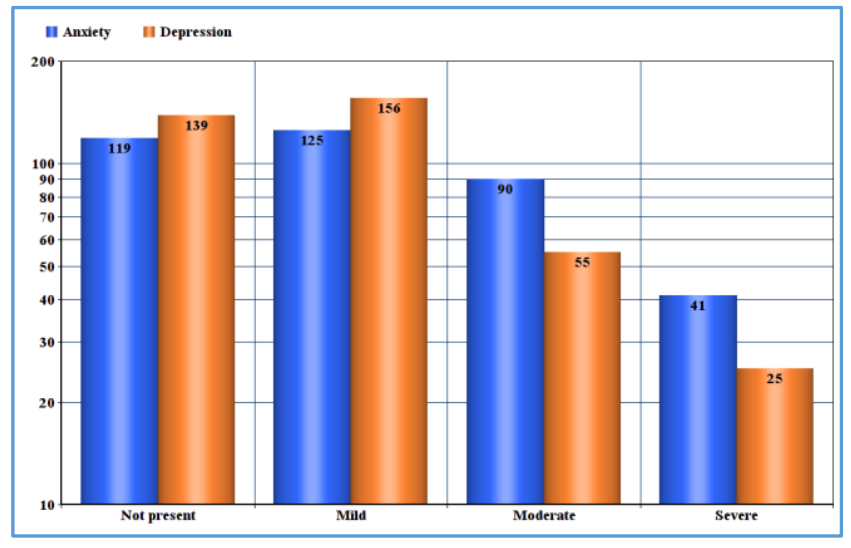

Figure 2. Anxiety and Depression among Study Group

\section{DISCUSSION}

Among non-gynaecological organic aetiologies of sexual dysfunction, the important complications of diabetes mellitus are hormonal imbalances, autonomic neuropathies (parasympathetic nervous system releases endothelial nitric oxide synthase, ENOS) and vascular insufficiency due to atherosclerosis.[33], Medications of DM are found to improve blood supply to clitoris.[34],[35] The important factors among the aetiologies of SD in diabetic women are neuropathies, vascular impairments and psychological discomforts.[36] Sexual health is often a neglected component of health care in diabetics. ${ }^{[37]} \mathrm{A}$ study by Wallner regarding sexual functioning among diabetic and non-diabetic women showed that type 2 DM patients experience similar sexual functioning to women without DM, but women with type $1 \mathrm{DM}$ report more sexual dysfunction such as dyspareunia. ${ }^{[38]}$

A study by Esposito in 2010 to evaluate the prevalence of sexual function in type $2 \mathrm{DM}$ showed the overall prevalence of female SD among the type 2 diabetic women was $53.4 \% .{ }^{[39]} \mathrm{A}$ review on female sexual disorders in women with DM reported that women were at higher risks for developing SD than non-diabetics.[40] Our study showed that $57.19 \%$ patients had problems in lubrication, $51.17 \%$ complained of decreased sexual desire, $47.49 \%$ had problems with arousal, $34.44 \%$ had dyspareunia, $63.21 \%$ complained of orgasmic dysfunction and $86.62 \%$ reported problems in sexual satisfaction [Figure 1]. Copeland et al reported lower sexual satisfaction in diabetic women compared with non-diabetics, with an increased risk in insulin-treated diabetic women having problems with lubrication and orgasm.

Some studies showed a $20-78 \%$ decrease in sexual desire in female patients with diabetes with more prevalence in type 2 diabetes, while some studies found no or less prevalent effect.[41],[42] The risk of dyspareunia in diabetic women was observed to be up to $43 \%$, with increased prevalence in type 2 diabetes.[43] Many studies reported age as a determinant of SD in patients with DM.[44] Fattemi et al observed that age was negatively correlated with sexual functioning in type $2 \mathrm{DM}$ women.[45] Bitzer et al recommended that good glycaemic control in type 2 DM women for restoring normal sexual function. ${ }^{[46]}$

Our study showed a statistically significant association between age of the patient, BMI, HbA1C levels and duration of diabetes mellitus with sexual dysfunction [Table 5]. Our study also showed that there is significant prevalence of depression and anxiety among type 2 diabetic women [Figure 2].
Statistically significant correlation between depression and female SD was observed in our study. A review observed that the incidence of sexual problems in diabetic women have association with depression. ${ }^{[43]}$ Enzlin et al reported that SD in type 1 diabetic women was related to depression.[30] Minor episodes of depression can negatively affect the sexual desire in women. Poor control of diabetes and subsequent complications in women cause depressive episodes and sexual dysfunction.

\section{CONCLUSIONS}

Our study showed that there is high prevalence of sexual dysfunction (SD) in women with type 2 diabetes mellitus (DM). Our study also showed that there is statistical significant association between complications of diabetes mellitus and prevalence of sexual dysfunction. Patients with type 2 diabetes mellitus have higher prevalence of depression and anxiety. There is strong correlation between sexual dysfunction and age of the patient, BMI, HbA1C levels and duration of diabetes mellitus.

Sexual health and problems are commonly neglected in daily practice of physicians especially among female patients and many patients consider discussing it as a taboo even though there are significant improvements in perceptions regarding sexual health. Health care professionals should be aware of the possible presence of sexual dysfunction in female diabetic patients in their practice to improve the quality of life. Appropriate methods for evaluating sexual function in women should be used to diagnose pathology and start appropriate management.

\section{REFERENCES}

1. Ahmed AM. History of diabetes mellitus. Saudi Med J 2002;23(4):373-8.

2. Diabetes mellitus history- from ancient to modern times. 2011. http://science.jrank.org/pages/2044/DiabetesMellitus. html 2011.

3. Patlak M. New weapons to combat an ancient disease: treating diabetes. FASEB J 2002;16(14):1853.

4. Maitra A, Abbas AK. Endocrine system. In: Kumar V, Fausto $\mathrm{N}$, Abbas AK. eds. Robbins and Cotran pathologic basis of disease. $7^{\text {th }}$ edn. Philadelphia, Saunders 2005:1156-1226.

5. Chen L, Magliano DJ, Zimmet PZ. The worldwide epidemiology of type 2 diabetes mellitus: present and future perspectives. Nature Reviews Endocrinology 2011;8(4):228-36.

6. Genetic basis of type 1 and type 2 diabetes, obesity and their complications. Advances and emerging opportunities in diabetes research: a strategic planning report of the DMICC. 2011. www2.niddk.nih.gov/NR 2011.

7. International Diabetes Federation. 2016. P. 13.

8. Melmed S, Polonsky K, Larsen PR, et al. Williams textbook of endocrinology. $12^{\text {th }}$ edn. Philadelphia: Elsevier/Saunders. 2012:1371-1435. ISBN 978-1-43770324-5.

9. Shi Y, Hu FB. The global implications of diabetes and cancer. The Lancet 2014;383(9933):1947-8.

10. Vos T, Flaxman AD, Naghavi M, et al. Years lived with disability (YLDs) for 1160 sequelae of 289 diseases and injuries 1990-2010: a systematic analysis for the Global Burden of Disease Study 2010. Lancet 2012;380(9859): 2163-96. 
11. International Diabetes Federation. 2014.

12. IDF Diabetes Atlas (PDF). $6^{\text {th }}$ edn. International Diabetes Federation. 2013. p. 7. ISBN 2930229853.

13. American Diabetes Association. Economic costs of diabetes in the U.S. in 2012. Diabetes Care 2013;36(4):1033-46.

14. Truglio-Londrigan M, Lewenson S. Public health nursing: practicing population-based care. $2^{\text {nd }}$ edn. Burlington, Mass: Jones \& Bartlett Learning 2013. p. 317. ISBN 9781449646608.

15. Smyth S, Heron A. Diabetes and obesity: the twin epidemics. Nature Medicine 2006;12(1):75-80.

16. Global Burden of Disease Study 2013 Collaborators. Global, regional and national incidence, prevalence, and years lived with disability for 301 acute and chronic diseases and injuries in 188 countries, 1990-2013: a systematic analysis for the Global Burden of Disease Study 2013. Lancet 2015;386(9995):743-800.

17. Wild S, Roglic G, Green A, et al. Global prevalence of diabetes: estimates for the year 2000 and projections for 2030. Diabetes Care 2004;27(5):1047-53.

18. Diabetes Fact sheet No 312. World Health Organization. 2011.

19. Ripoll, Leutholtz BC, Ignacio. Exercise and disease management. $2^{\text {nd }}$ edn. Boca Raton: CRC Press 2011. p. 25. ISBN 978-1-4398-2759-8.

20. Zaccardi F, Webb DR, Yates T, et al. Pathophysiology of type 1 and type 2 diabetes mellitus: a 90-year perspective. Postgraduate Medical Journal 2016;92(1084):63-9.

21. Ripsin CM, Kang H, Urban RJ. Management of blood glucose in type 2 diabetes mellitus. Am Fam Physician 2009;79(1):29-36.

22. Hu FB, Manson JE, Stampfer MJ, et al. Diet, lifestyle and the risk of type 2 diabetes mellitus in women. $\mathrm{N}$ Engl J Med 2001;345(11):790-7.

23. Prevalence of overweight and obesity among adults with diagnosed diabetes-United States, 1988-1994 and 1999 2002. Centers for Disease Control and Prevention (CDC). MMWR Morb Mortal Wkly Report 2004;53(45):1066-68.

24. Bachmann GA, Phillips NA. Sexual dysfunction. In: Steege JF, Metzger DA, Levy BS. eds. Chronic pelvic pain: an integrated approach. Philadelphia: Saunders 1998:77-90.

25. ACOG technical bulletin. Sexual dysfunction: No. 211. September 1995. International J Gynecology and Obstetrics 1995;51(3):265-77.

26. Bachmann GA, Leiblum SR, Grill J. Brief sexual inquiry in gynecologic practice. Obstet Gynecol 1989;73(3 Pt 1):4257.

27. Angst J. Sexual problems in healthy and depressed persons. Int Clin Psychopharmacol 1998;13(Suppl 6):S1-4

28. Read S, King M, Watson J. Sexual dysfunction in primary medical care: prevalence, characteristics and detection by the general practitioner. J Public Health Med 1997;19(4):387-91.
29. Enzlin P, Mathieu C, van den Bruel A, et al. Sexual dysfunction in women with type 1 diabetes: a controlled study. Diabetes Care 2002;25(4):672-7.

30. Miočić J, Car N, Metelko Ž. Sexual dysfunction in women with diabetes mellitus. Diabetol Croat 2008;37(2):35-42.

31. Rosen R, Brown C, Heiman J, et al. The Female Sexual Function Index (FSFI): a multidimensional self-report instrument for the assessment of female sexual function. J Sex Marital Ther 2000;26(2):191-208.

32. Herrmann C. International experiences with the Hospital Anxiety And Depression Scale-a review of validation data and clinical results. J Psychosom Res 1997;42(1):17-41.

33. Zigmond AS, Snaith RP. The hospital anxiety and depression scale. Acta Psychiatr Scand 1983;67(6):361-70.

34. Kendirci M, Trost L, Sikka SC, et al. The effect of vascular risk factors on penile vascular status in men with erectile dysfunction. J Urol 2007;178(6):2516-20.

35. Erol B, Tefekli A, Sanli 0, et al. Does sexual dysfunction correlate with deterioration of somatic sensory system in diabetic women? Int J Impot Res 2003;15(3):198-202.

36. Caruso S, Rugolo S, Mirabella D, et al. Changes in clitoral blood flow in premenopausal women affected by type 1 diabetes after single 100-mg administration of sildenafil. Urology 2006;68(1):161-5.

37. Amaral S, Oliveira PJ, Ramalho-Santos J. Diabetes and the impairment of reproductive function: possible role of mitochondria and reactive oxygen species. Curr Diabetes Rev 2008;4(1):46-54.

38. Fatemi SS, Taghavi SM. Evaluation of sexual function in women with type 2 diabetes mellitus. Diab Vasc Dis Res 2009;6(1):38-9.

39. Wallner LP, Sarma AV, Kim C. Sexual functioning among women with and without diabetes in the Boston area community health study. J Sex Med 2010;7(2 Pt 2):881-7.

40. Esposito K, Maiorino MI, Bellastella G, et al. Determinants of female sexual dysfunction in type 2 diabetes. Int J Impot Res 2010;22(3):179-84.

41. Giraldi A, Kristensen E. Sexual dysfunction in women with diabetes mellitus. J Sex Res 2010;47(2):199-211.

42. Mezones-Holguin E, Blumel JE, Huezo M, et al. Impact of diabetes mellitus on the sexuality of Peruvian postmenopausal. Gynecol Endocrinol 2008;24(8):470-4.

43. Ogbera AO, Chinenye S, Akinlade A, et al. Frequency and correlates of sexual dysfunction in women with diabetes mellitus. J Sex Med 2009;6(12):3401-6.

44. Bargiota A, Dimitropoulos K, Tzortzis V, et al. Sexual dysfunction in diabetic women. Hormones (Athens) 2011;10(3):196-206.

45. Muniyappa R, Norton M, Dunn ME, et al. Diabetes and female sexual dysfunction: moving beyond "benign neglect". Curr Diab Rep 2005;5(3):230-6.

46. Bitzer J, Alder J. Diabetes and female sexual health. Womens Health (Lond) 2009;5(6):629-36. 